04

\title{
Электронно-лучевая зарядка диэлектриков, предварительно облученных ионами и электронами средних энергий
}

\author{
( Э.И. Рау, А.А. Татаринцев, Е.Ю. Зыкова, И.П. Иваненко, С.Ю. Купреенко, \\ К.Ф. Миннебаев, А.А. Хайдаров
}

Московский государственный университет им. М.В. Ломоносова, Москва, Россия

E-mail: rau@phys.msu.ru

(Поступила в Редакцию 28 декабря 2016 г.

В окончательной редакции 14 февраля 2017 г.)

\begin{abstract}
Изучены эффекты зарядки диэлектрических мишеней при облучении электронами средних энергий в сканирующем электронном микроскопе. Установлены существенные различия кинетики зарядки для исходных образцов и образцов, предварительно облученных электронами и ионами. Эти различия объясняются радиационно-стимулированным дефектообразованием в образцах $\mathrm{Al}_{2} \mathrm{O}_{3}$ (сапфир) и $\mathrm{SiO}_{2}$, имеющим, однако, различную природу. Показана роль модификации структуры поверхности и изменения электрофизических характеристик поверхности, в частности эффекта растекания зарядов. Обнаружены критические значения дозы облучения как ионами $\mathrm{Ar}^{+}$, так и электронами, при которых начинается активное дефектообразование в диэлектрических мишенях, а также критические значения внутренних полей зарядов, вносящих существенный вклад во временны́е характеристики зарядки $\mathrm{Al}_{2} \mathrm{O}_{3}$ и $\mathrm{SiO}_{2}$.
\end{abstract}

Работа выполнена при финансовой поддержке РФФИ (грант № 15-02-07819а).

DOI: $10.21883 /$ FTT.2017.08.44749.460

\section{1. Введение}

При взаимодействии электронных и ионных пучков с диэлектрическими мишенями происходят модификация поверхностной структуры и изменения электрофизических свойств. В значительной степени это обусловлено зарядкой поверхности облучаемого образца. Эффекты зарядки диэлектриков играют большую роль в радиационной физике, эмиссионной электронике, электроннозондовых и ионно-лучевых методах анализа структуры и состава твердого тела, а также в вопросах обеспечения надежности космических аппаратов. Кроме того, сфокусированные пучки электронов и ионов в последнее время широко используются в различных технологических процессах в микро- и наноэлектронике.

В связи с этим в последние годы проводятся обширные исследования механизмов зарядки диэлектрических компонентов образцов при электронном и ионном облучении. Но если явление зарядки электронными пучками достаточно хорошо изучено [1-7], то проблемам зарядки диэлектрических мишеней под воздействием ионной бомбардировки посвящены лишь единичные работы [8-11]. Также лишь в отдельных работах было проведено исследование процессов электронной зарядки диэлектрических сред после их предварительного облучения ионными и электронными пучками $[12,13]$.

Информация, изложенная в указанных работах, носит отрывочный характер. В них представлены, как правило, результаты первых экспериментов по рассматриваемой тематике. Так, в [8] впервые изучалась зарядка $\mathrm{SiO}_{2}$ при облучении ионами $\mathrm{He}^{+}$с энергией $1-4 \mathrm{keV}$ и было показано, что при возрастании дозы облучения вначале приобретается отрицательный потенциал (до $V_{s}=-50 \mathrm{~V}$ ), затем $V_{s}$ проходит нулевое значение, после чего возрастает до равновесной величины от +25 до $+50 \mathrm{~V}$ в зависимости от энергии бомбардирующих ионов. Оказалось, что при возрастании энергии $\mathrm{He}^{+}$ положительный потенциал зарядки уменьшается. Но эта интересная работа поставила больше вопросов, чем дала ответов.

Ионно-индуцированная зарядка тонких пленок $\mathrm{SiO}_{2}$, конденсированных пленок инертных газов, а также алмаза, происходящая при бомбардировке ионами $\mathrm{Ar}^{+}$, $\mathrm{Ga}^{+}$, протонами с энергией в единицы $\mathrm{keV}$, также показала, что диэлектрики заряжаются положительно до потенциала в единицы-десятки вольт [9-12]. Неожиданный скачкообразный характер процесса зарядки алмаза после ионной бомбардировки $\left(\mathrm{Ar}^{+}\right)$различными дозами обнаружен в работе [12]. Измерения, проведенные по сдвигу Оже-пиков, показали, что при энергии облучающих электронов $E_{0}=1 \mathrm{keV}$ алмаз заряжается отрицательно до $V_{s}=-170 \mathrm{~V}$, затем значение отрицательного потенциала изменяется постепенно до нуля. Такой реверсивный характер процесса зарядки авторы объясняют тем, что при определенной (критической) дозе ионного облучения $\left(2 \cdot 10^{15} \mathrm{~cm}^{-2}\right)$ происходит почти скачкообразная трансформация структуры алмаза в графитоподобную. В работе [13] впервые исследовалось влияние предварительной бомбардировки сапфира ионами $\mathrm{Ar}^{+} \mathrm{c}$ энергией $10 \mathrm{keV}$ при дозах облучения $10^{18}-10^{19} \mathrm{~cm}^{-2}$. Указанные дозы настолько велики, что значительно видоизменяли поверхностный микрорельеф кристалла, 
вследствие чего происходило снижение коэффициента вторичной электронной эмиссии. Но в настоящей работе установлено, что указанная причина не является единственной (и даже доминирующей), ответственной за особенности кинетики зарядки сапфира.

Механизм зарядки диэлектрика под воздействием электронного облучения к настоящему времени в общих чертах разработан. Его основу составляет двухслойная модель зарядки мишени, теоретически предложенная в работах [1-3] и подтвержденная рядом экспериментов [4-7]. Согласно этой модели, при электронной бомбардировке диэлектрической мишени вблизи ее поверхности образуется слой положительного заряда изза эмиссии вторичных электронов (ВЭ). Толщина этого слоя $\lambda$, определяемая глубиной выхода ВЭ, равна единицам-десяткам нанометров. Одновременно образуется более протяженный слой отрицательного заряда, образованный частью первичных электронов, аккумулированных на глубоких и мелких уровнях ловушечных дефектов. Толщина этого слоя приблизительно равна глубине пробега первичных электронов $R_{0}$ (порядка долей единиц микрометров). Если общий коэффициент эмиссии электронов $\sigma>1$, то поверхность образца заряжается положительно; если $\sigma<1$, то отрицательно. При равенстве положительного и отрицательного зарядов $Q_{+}=Q_{-}$образец не заряжается, и поверхностный потенциал $V_{s}=0$. Это справедливо лишь при определенной критической энергии $E_{0}=E_{2 C}$ облучающих электронов, при которой глубина их проникновения $R_{0} \approx 3 \lambda$.

Отметим, что в этой трактовке зарядки диэлектрика до сих пор остаются дискуссионные вопросы, в частности противоречия в теоретических и экспериментальных работах (см., например, [1-7]) между приводимыми значениями времен зарядки и критической энергии $E_{2 C}$. Причина этого противоречия, на наш взгляд, состоит в различии подходов к установлению взаимосвязи кинетики поверхностных потенциалов $V_{s}$ и коэффициентов эмиссии электронов $\sigma$ для заряжающихся в процессе облучения мишеней.

Механизм зарядки диэлектриков при ионном облучении практически не изучен, что объясняется, вероятно, сложностью как расчетов, так и постановки экспериментов. В последние годы, однако, в значительной степени возрос интерес к этой проблеме из-за актуальности применения ионно-лучевых технологий в современных методах анализа, а также в области наноиндустрии.

При бомбардировке поверхности оксидов ионами низких энергий может происходить целый ряд различных процессов, таких как распыление поверхности, внедрение (имплантация) ионов, радиационное дефектообразование, изменение кристаллической структуры, развитие поверхностного рельефа [14]. Эксперименты по ионному распылению оксидов металлов показали, что при бомбардировке ионами низких энергий $(<10 \mathrm{keV})$ многих оксидов наблюдается преимущественное распыление кислорода. Потеря кислорода приводит к образованию на поверхности фазы с меньшей степенью окисления, а в некоторых случаях - к появлению восстановленной металлической фазы. В результате на поверхности оксида формируется тонкий (до $2.5 \mathrm{~nm}$ ) измененный слой, по составу отличный от стехиометрического исходного диэлектрика $[15,16]$.

Если падающий ион при упругом столкновении передает атому поверхности энергию, превышающую пороговую энергию смещения, то в результате генерируется френкелевская пара дефектов (вакансия и междоузельный атом). Число создаваемых ионным облучением дефектов пропорционально энергии падающих ионов и дозе ионного облучения. Дефекты в кристалле могут образовываться вплоть до глубины проникновения первичных ионов в кристалл, которая при энергии ионов менее $10 \mathrm{keV}$ составляет величину порядка нескольких нанометров. При больших дозах ионного облучения создается так много дефектов, что происходит аморфизация поверхности, т. е. потеря кристаллической структуры. Необходимым условием аморфизации облучаемой ионами области кристалла является пространственное разделение в этой области вакансий и междоузельных атомов. На основании теоретических расчетов критическая концентрация смещенных атомов, необходимая для аморфизации, должна составлять 0.05-0.2 от атомной плотности кристалла.

В ходе ионной бомбардировки на первоначально плоской поверхности формируется рельеф: появляется множество впадин и выступов неправильной формы. При небольших дозах облучения, не превышающих $10^{16} \mathrm{~cm}^{-2}$, в процессе распыления под действием ионной бомбардировки возникают поверхностные неоднородности атомного масштаба. При больших дозах наблюдаются микроскопические неоднородности с размерами порядка $10-1000 \mathrm{~nm}$, образуются ямки травления, конические или пирамидальные выступы, а также волнистые структуры типа „ряби“ [14].

В отличие от ионного облучения бомбардировка поверхности твердых тел низкоэнергетическими электронами (с энергиями порядка нескольких $\mathrm{keV}$ ) не может приводить к созданию стабильных френкелевских пар дефектов за счет упругих столкновений. Это связано с тем, что из-за малости массы электрона энергия, передаваемая атому при упругом столкновении, оказывается слишком малой для смещения атома из его положения в кристаллической решетке. Однако экспериментальные данные свидетельствуют о том, что даже низкоэнергетические электроны с энергиями в несколько десятков $\mathrm{eV}$ способны разрушать поверхность некоторых материалов и создавать в кристалле пары точечных дефектов (вакансии и междоузельные атомы). Разрушение поверхности твердого тела низкоэнергетическими электронами получило название электронно-стимулированной десорбции (ЭСД).

Для объяснения ЭСД с поверхности оксидов обычно привлекают механизм Кнотека-Фейбельмана (КФ) [17], который был разработан для оксидов с максимальной 
степенью окисления. Согласно КФ-модели, первичный электрон создает вакансию на остовном электронном уровне атома металла, которая может заполняться только за счет межатомного Оже-процесса, поскольку своих свободных электронов у атома металла нет. В результате заполнение остовной дырки сопровождается выходом из валентной зоны одного или двух электронов. Потеряв два или три электрона, ион $\mathrm{O}^{2-}$ становится нейтральной частицей $\mathrm{O}^{0}$ или положительным ионом $\mathrm{O}^{+}$и может десорбироваться за счет кулоновского отталкивания.

Таким образом, при ионной и электронной бомбардировке диэлектрика происходит радиационно-стимулированная модификация поверхности. Изменяются как структура, так и электрофизические свойства, в том числе изменяются характеристики зарядки мишеней, предварительно облученных электронами средних энергий. Более детальному исследованию этого малоизученного явления посвящена настоящая работа. Обнаружен ряд специфических особенностей в кинетике зарядки диэлектриков, которые не были описаны в известных нам предыдущих работах.

\section{2. Образцы и методика экспериментов}

Исследовались два классических диэлектрика: монокристаллы $\mathrm{Al}_{2} \mathrm{O}_{3}$ (сапфир) и $\mathrm{SiO}_{2}$. Размер исследованных пластин составлял $10 \times 10 \times 1 \mathrm{~mm}$. Образцы предварительно облучались различными дозами ионных пучков $\mathrm{Ar}^{+}$с энергией 10 кэВ и электронами с энергией $1 \mathrm{keV}$ в высоком вакууме $\left(10^{-8} \mathrm{Torr}\right)$. Изменения морфологии поверхности после проведенной бомбардировки пучками заряженных частиц наблюдались с помощью атомно-силового микроскопа (АСМ). На рис. 1 приводятся типичные изображения рельефа поверхности сапфира после облучения ионами $\mathrm{Ar}^{+}$с дозой $10^{17} \mathrm{~cm}^{-2}(b)$ и электронами с дозой $2 \cdot 10^{20} \mathrm{~cm}^{-2}(c)$. В обоих случаях видна структура образовавшейся в результате облучения островковой пленки. Образование пленки происходит в результате десорбции кислорода при бомбардировке $\mathrm{SiO}_{2}$ и $\mathrm{Al}_{2} \mathrm{O}_{3}$, при которой наблюдается частичная металлизация поверхности за счет формирования на ней островков алюминия, имеющих размеры порядка 50-70 nm [18]. Как показано далее, образование островковой пленки и частичная аморфизация поверхности играют большую роль в зарядке диэлектрика, но при этом проявляются весьма существенные различия между $\mathrm{SiO}_{2}$ и $\mathrm{Al}_{2} \mathrm{O}_{3}$.

Экспериментальная установка, использованная в настоящей работе, подробно описана в работе [13], поэтому отметим здесь только основные особенности методики измерений. Во-первых, для правильной интерпретации результатов необходимо снимать все временны́е характеристики зарядки образца одновременно. Для этого в сканирующий электронный микроскоп (СЭМ) монтируется комплексное устройство, позволяющее измерять поверхностные потенциалы $V_{s}$ (по сдвигу спектров ВЭ), токи утечки и смещения $I_{L+D}$ (для определения аккумулированного заряда $Q_{t}$ ), токи вторичной электронной эмиссии $I_{\sigma}$, а также при необходимости детектировать сигналы катодолюминесценции и рентгеновского излучения. Во-вторых, измеряемые характеристики регистрируются в зависимости от времени облучения электрон-
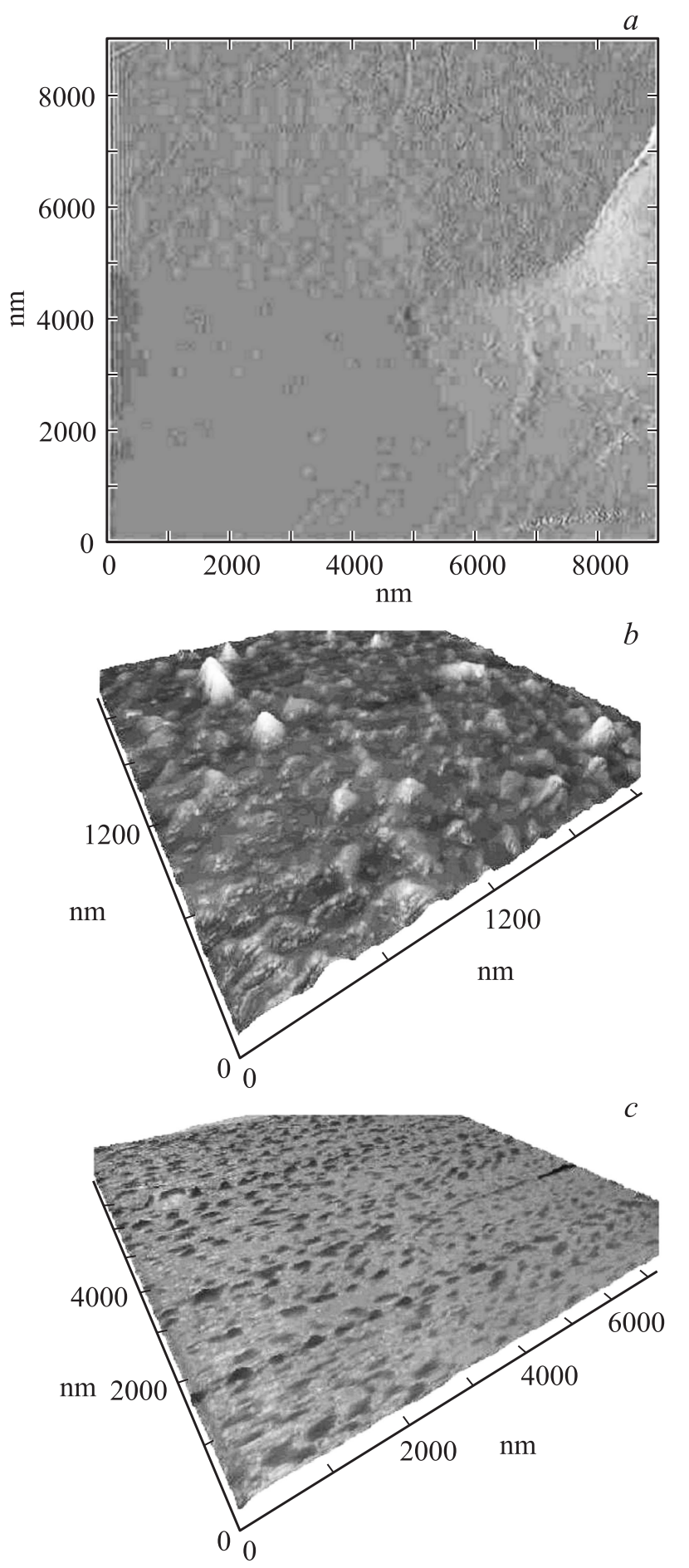

Рис. 1. АСМ-изображения грани (0001) сапфира. $a-$ необлученная поверхность, $b-$ после облучения ионами $\mathrm{Ar}^{+}$с дозой $10^{17} \mathrm{~cm}^{-2}, c-$ после облучения электронами с дозой $2 \cdot 10^{20} \mathrm{~cm}^{-2}$. 
ным зондом СЭМ, т. е. регистрируется кинетика зарядки вплоть до наступления состояния насыщения, когда все характеристики достигают равновесных значений.

В процессе облучения в СЭМ диэлектрической мишени электронным пучком с энергией $E_{0}>E_{2 C}$ и током $I_{0}$ образец заряжается отрицательно до потенциала $V_{s}(t)=\left(E_{0}-E_{L}(t)\right) / e$, где $E_{L}-$ фактическая энергия электронов падающего пучка, $E_{2 C}-$ энергия $E_{0}$, при которой зарядка достигает равновесного значения, когда $I_{\sigma}=I_{0}$. При увеличении $V_{s}(t)$ уменьшается $E_{L}(t)$, что вызывает рост эмиссии электронов, т.е. тока $I_{\sigma}(t)$ при одновременном уменьшении тока смещения $I_{D}$. Одновременная регистрация кинетики всех перечисленных сигналов позволяет воссоздать полную картину механизма зарядки диэлектрических мишеней под воздействием электронного облучения.

\section{3. Результаты измерений}

В процессе облучения сапфира ионами $\mathrm{Ar}^{+}$с энергией $10 \mathrm{keV}$ одновременно измерялись энергетические спектры $\mathrm{Al}^{+}$, по сдвигам которых определялся потенциал зарядки. Результаты таких измерений, проведенных после трех набранных доз $D$, представлены на рис. 2.

После дозы облучения $D_{1}=5 \cdot 10^{15} \mathrm{~cm}^{-2}$ эффектов зарядки не обнаружено (кривая 1), но после дозы $10^{16} \mathrm{~cm}^{-2}$ пики $\mathrm{Al}^{+}$начинают раздваиваться, и второй пик смещается по энергетической оси до максимального значения $V_{s}=+70 \mathrm{~V}$, достигаемого при дозе $D_{2}=2 \cdot 10^{17} \mathrm{~cm}^{-2}$ (кривая 2). После этого начинается внезапный спад потенциала и реализуется его приход в равновесное состояние $V_{s}=+40 \mathrm{~V}$ при дозе $D_{3}=3 \cdot 10^{17} \mathrm{~cm}^{-2}$ (кривая 3).

Возможное объяснение этого феномена - быстрая аморфизация поверхности сапфира при критической дозе облучения $D_{2}=2 \cdot 10^{17} \mathrm{~cm}^{-2}$. Механизм этого явления, а также тот парадоксальный факт, что первый пик в энергетическом распределении $\mathrm{Al}^{+}$не сдвигается при зарядке (кривая 1), требуют более детального

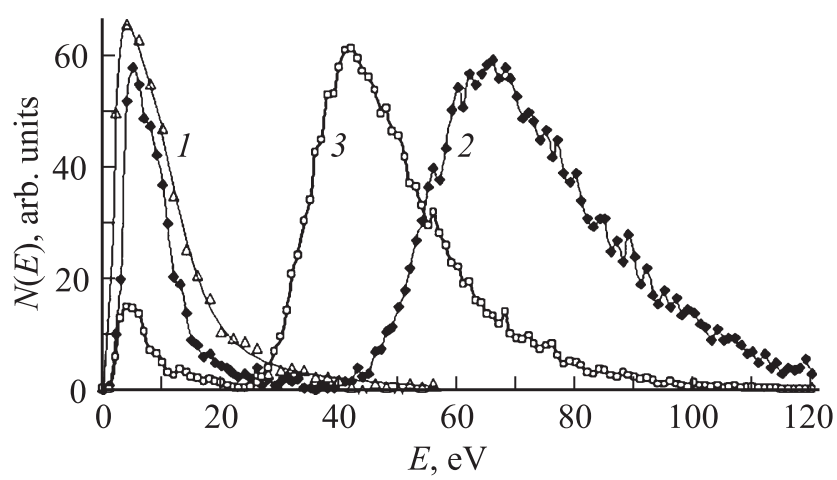

Рис. 2. Энергетические спектры $\mathrm{Al}^{+}$, измеренные в процессе облучения сапфира ионами $\mathrm{Ar}^{+}$с различными дозами. $1-D_{1}=5 \cdot 10^{15} \mathrm{~cm}^{-2}, 2-D_{2}=2 \cdot 10^{17} \mathrm{~cm}^{-2}, 3-$ $D_{3}=3 \cdot 10^{17} \mathrm{~cm}^{-2}$. Энергия ионов $\mathrm{Ar}^{+} 10 \mathrm{keV}$. исследования. Наличие двух пиков в спектрах $\mathrm{Al}^{+}$ было зафиксировано также в работе [19], где описана природа их образования (на наш взгляд, дискуссионная). Представляет большой интерес тот факт, что при электронном облучении сапфира, как показано далее, также существует критическая доза, до набора которой не происходит зарядки, а после ее достижения сапфир начинает интенсивно заряжаться.

Далее изложены результаты измерения кинетики поверхностных потенциалов $\mathrm{Al}_{2} \mathrm{O}_{3}$ и $\mathrm{SiO}_{2}$ при их облучении электронами с энергией 5 и $15 \mathrm{keV}$. Во всех случаях измерения проводились как на исходных образцах, так и на предварительно облученных ионными и электронными пучками определенной дозы. На рис. 3, $a$ приводятся результаты измерений зависимостей $V_{s}(t)$ для сапфира, измеренные при плотности электронного тока $j_{0}=10^{-5} \mathrm{~A} \cdot \mathrm{cm}^{-2}$. Для исходного (необлученного заряженными частицами) сапфира, судя по кривым 1 на рис. $3, a, b$, существуют критические дозы электронного облучения порядка $D=e j_{0} t \sim 5 \cdot 10^{16} \mathrm{~cm}^{-2}$ (где $e-$ заряд электрона, $t$ - время облучения), до которых зарядки не происходит, а после них отрицательный потенциал $V_{s}$ прогрессивно нарастает, достигая равновесного значения при довольно больших дозах (порядка $3 \cdot 10^{17} \mathrm{~cm}^{-2}$ ). Такая закономерность зарядки сапфира наблюдалась и ранее (см., например, $[2,13,20,21]$ ) и может быть объяснена следующим образом [20,21]. Изначально чистый сапфир не имеет дефектов кристаллической структуры, поэтому не склонен заряжаться при электронном облучении. Но со временем генерируется все больше радиационно-стимулированных дефектов, в частности вакансий кислорода ( $F$-центры), которые являются ловушками для электронов. Необходимо также учитывать вклад частичной металлизации поверхности за счет образования островков алюминия [18]. При предварительной бомбардировке сапфира ионами $\mathrm{Ar}^{+} \mathrm{c}$ энергией $10 \mathrm{keV}$ и дозой порядка $10^{17} \mathrm{~cm}^{-2}$ создается достаточное число дефектов, чтобы интенсивно захватывать электроны на уже генерированные ионами ловушки (см. кривые 3 на рис. 3, $a, b)$. Поэтому время зарядки сапфира, предварительно облученного ионами $\mathrm{Ar}^{+}$, на три порядка меньше времени зарядки исходного, не подвергнутого предварительной ионной бомбардировке (см. кривые 1 и 3 на рис. 3).

Что касается влияния на кинетику зарядки предварительного облучения сапфира электронными пучками, то заметно некоторое различие в случае измерений при 5 и $15 \mathrm{keV}$ (кривые 2 на рис. 3, $a, b)$. При энергии облучающих электронов $E_{0}=5 \mathrm{keV}$ характер зарядки аналогичен наблюдаемому для сапфира, предварительно облученного ионами $\mathrm{Ar}^{+}$(cp. кривые 2 и 3 на рис. $3, a$ ). Но при энергии облучающих электронов $E_{0}=15 \mathrm{keV}$ обнаруживается следующая необычная закономерность: в начальные моменты облучения (единицы секунд) сапфир быстро заряжается до некоторого критического потенциала $V_{s}=-2.5 \mathrm{kV}$, после чего процесс зарядки резко замедляется, и потенциал поверхности достигает 

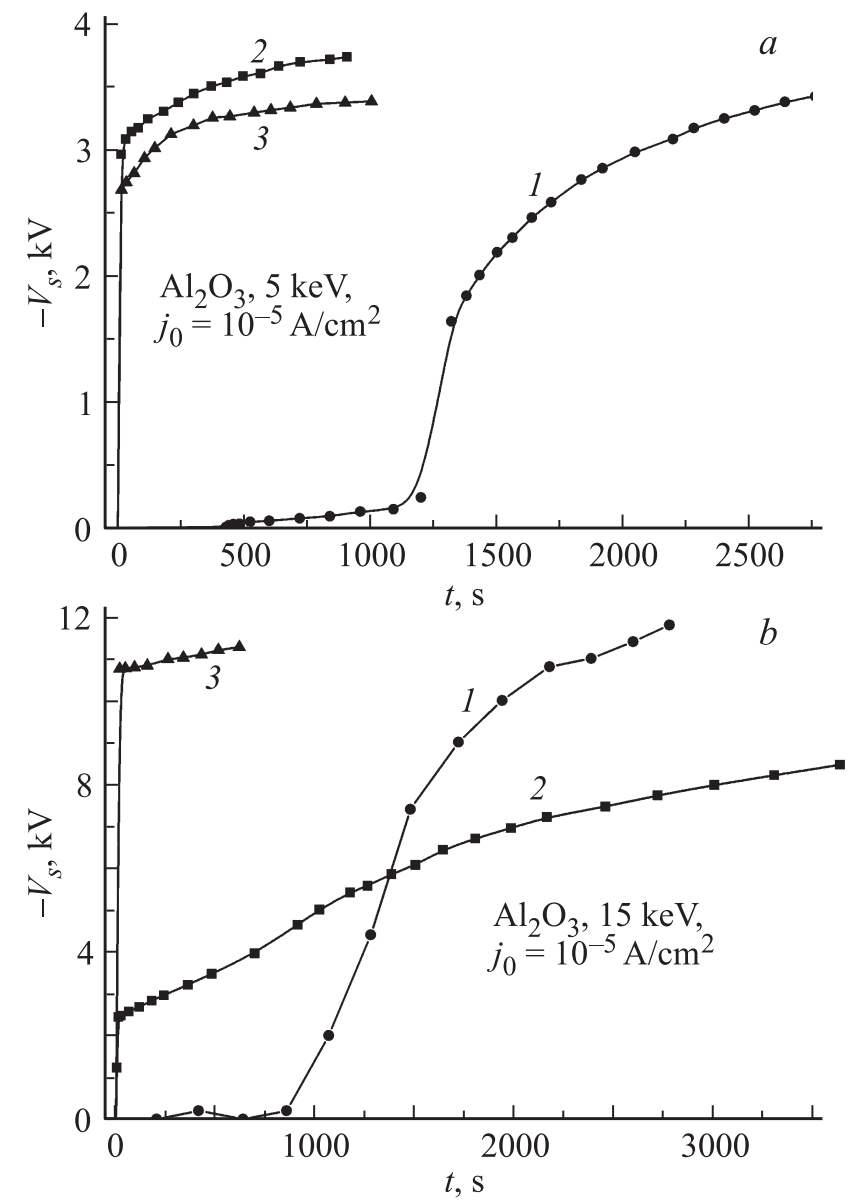

Рис. 3. Зависимость потенциала $V_{s}$ заряжающейся поверхности сапфира от времени облучения электронами с плотностью тока $j_{0}=10^{-5} \mathrm{~A} / \mathrm{cm}^{2}$ и энергией $E_{0}=5$ (a) и $15 \mathrm{keV}(b)$. 1 - исходная поверхность, 2 - поверхность, предварительно облученная электронами с дозой $2 \cdot 10^{20} \mathrm{~cm}^{-2}$ и энергией $1 \mathrm{keV}, 3$ - поверхность, предварительно облученная ионами с дозой $10^{17} \mathrm{~cm}^{-2}$ и энергией $10 \mathrm{keV}$.

равновесного значения спустя время, на порядок большее, чем при $E_{0}=5 \mathrm{keV}$ (кривая 2 на рис. $3, b$ ), и в разы большее, чем при зарядке исходного сапфира (кривая 1 на рис. $3, b)$. Столь неожиданный характер кинетики зарядки можно объяснить следующим образом. Как видно из рис. 1, при предварительном облучении сапфира пучком электронов на поверхности образуются островки алюминия с диаметром $10^{-} 20 \mathrm{~nm}$ и приблизительно с таким же расстоянием между островками. Диаметр пятна предварительного электронного облучения на поверхности, где образованы островки Al, равен $3 \mathrm{~mm}$. При измерении поверхностных потенциалов облучается площадка сканирования электронным зондом СЭМ размером $100 \times 100 \mu \mathrm{m}^{2}$, находящаяся в центре предварительного облученного участка $(3 \mathrm{~mm})$. В итоге непосредственно заряжается только сканируемая площадка, но после достижения некоторого критического потенциала $\left(V_{s}=-2.5 \mathrm{kV}\right)$ генерируемое при зарядке электрическое поле вызывает растекание электронов по поверхности, где уже предварительной электронной бомбардировкой созданы условия для прыжковой проводимости электронов через металлические (алюминиевые) островки. Возможность такого механизма следует из оценки средней длины свободного пробега $\lambda$ электрона в диэлектрике под действием внутреннего поля $F_{\text {in }}-$ так называемой длины „Schubweg“ $[1-3]$

$$
\lambda=\mu_{e} F_{\text {in }} \tau
$$

где $\mu_{e}-$ подвижность электронов, $\tau-$ их время жизни. При $F_{\text {in }}$, равном по порядку величины единицам $\mathrm{kV} \cdot \mathrm{cm}^{-1}, \lambda$ может достигать десятков нанометров, что сравнимо с диаметром островков $\mathrm{Al}$ и расстоянием между ними. Более подробно этот механизм рассмотрен далее. Судя по данным рис. $3, a, b$, критическое поле, приводящее к прыжковому растеканию зарядов, образуется при потенциале $2.5-3 \mathrm{kV}$.
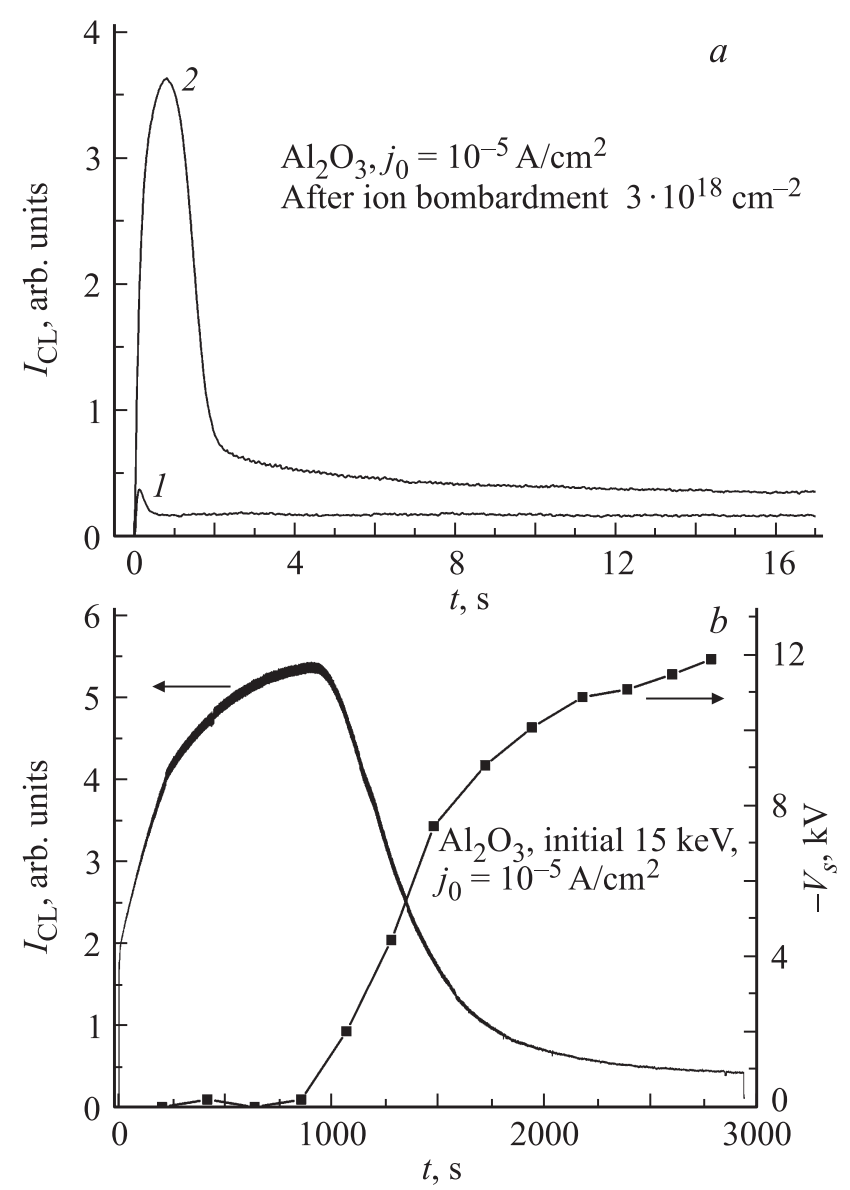

Рис. 4. а) Зависимости интенсивности катодолюминесценции от времени облучения электронами с плотностью тока $j_{0}=10^{-5} \mathrm{~A} \cdot \mathrm{cm}^{-2}$ и энергией $E_{0}$, равной $5(1)$ и $15 \mathrm{keV}(2)$, для сапфира, предварительно облученного ионами $\mathrm{Ar}^{+}$c дозой $3 \cdot 10^{18} \mathrm{~cm}^{-2}$. b) Временна́я зависимость интенсивности катодолюминесценции и потенциала поверхности для исходной поверхности сапфира при электронном облучении с $j_{0}=10^{-5} \mathrm{~A} \cdot \mathrm{cm}^{-2}$ и $E_{0}=15 \mathrm{keV}$. 
Для подтверждения резкого различия времен зарядки исходного и облученного ионами сапфира приведем результаты сравнительных измерений катодолюминесцентного сигнала $I_{\mathrm{CL}}$ в зависимости от времени электронного облучения током с плотностью $j_{0}=10^{-5} \mathrm{~A} \cdot \mathrm{cm}^{-2}$ при $E_{0}=15 \mathrm{keV}$ (рис. 4).

При электронном облучении сапфира вначале наблюдается самоактивация, т.е. нарастание интенсивности катодолюминесцентного излучения. Затем, после достижения максимума сигнала $I_{\mathrm{CL}}$, наступает некоторый временной спад, вызванный как эффектом гашения [22], так и уменьшением энергии падающего пучка $E_{L}=E_{0}-e V_{s}$, вызванным тем, что поверхность заряжается отрицательно до потенциала $V_{s}(t)$. Моменты начала и завершения зарядки сапфира хорошо коррелируют с кинетикой сигнала $I_{\mathrm{CL}}$ : малые времена для ионно-облученного образца и очень большие времена облучения (дозы) для исходного образца.

Почти такая же картина наблюдается в случае зарядки $\mathrm{SiO}_{2}$ при электронном облучении, но есть и существен-
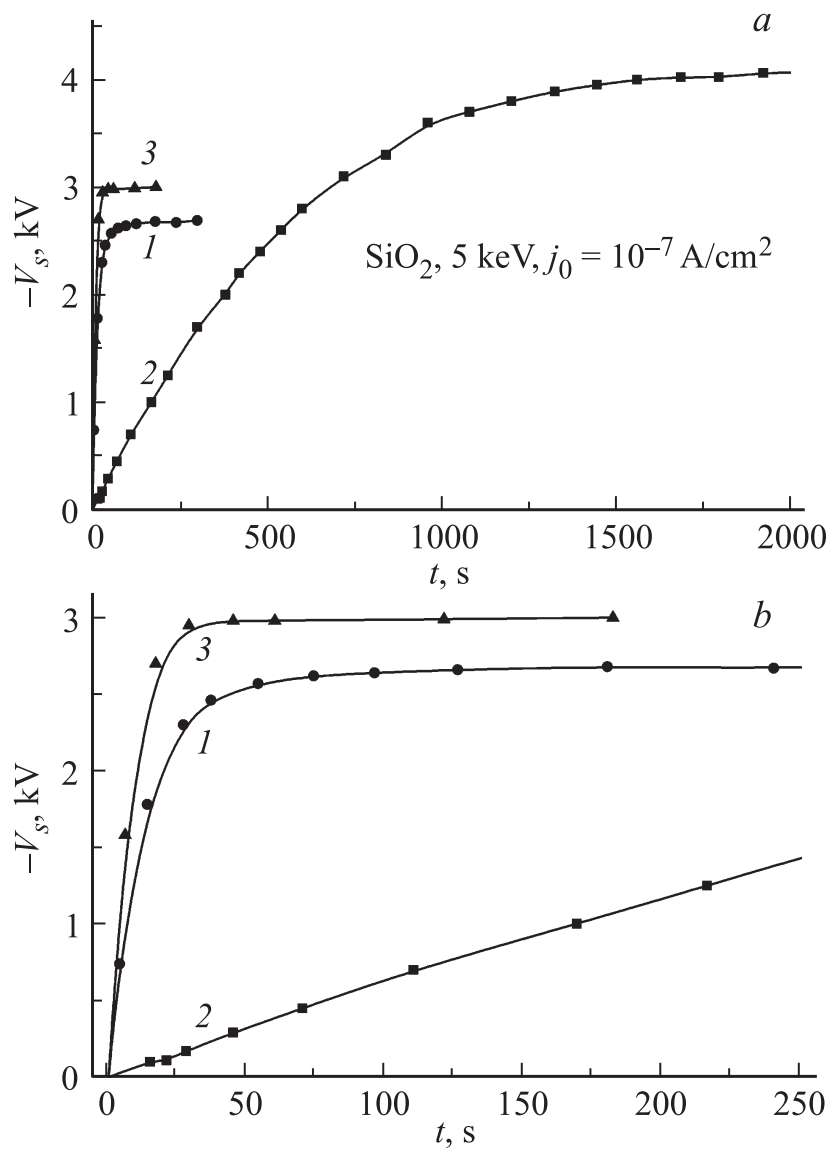

Pис. 5. $a)$ Временнб́е зависимости потенциала $V_{s}(t)$ поверхности $\mathrm{SiO}_{2}$, измеренные при $E_{0}=5 \mathrm{keV}$ и $j_{0}=10^{-7} \mathrm{~A} \cdot \mathrm{cm}^{-2}$. 1 - исходная поверхность, 2 - поверхность, предварительно облученная электронами с дозой $9 \cdot 10^{19} \mathrm{~cm}^{-2}$ и энергией $1 \mathrm{keV}, 3$ - поверхность, предварительно облученная ионами с дозой $10^{17} \mathrm{~cm}^{-2}$ и энергией $10 \mathrm{keV}$. b) То же в другом временно́м масштабе.

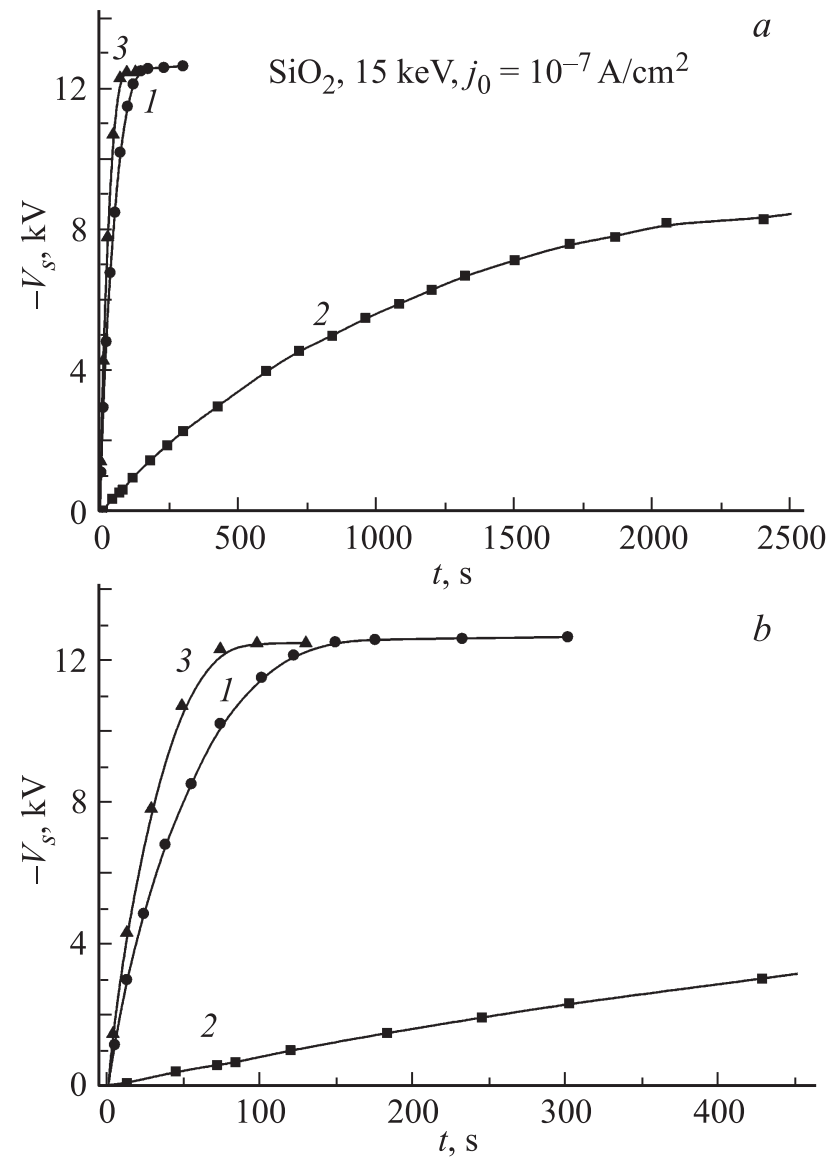

Рис. 6. a) Поверхностный потенциал $V_{s}$ как функция времени облучения поверхности $\mathrm{SiO}_{2}$ электронным зондом при $E_{0}=15 \mathrm{keV}$ и $j_{0}=10^{-7} \mathrm{~A} \cdot \mathrm{cm}^{-2} \cdot 1-$ исходная поверхность, 2 - поверхность, предварительно облученная электронами с дозой $9 \cdot 10^{19} \mathrm{~cm}^{-2}$ и энергией $1 \mathrm{keV}, 3-$ поверхность, предварительно облученная ионами с дозой $10^{17} \mathrm{~cm}^{-2}$ и энергией $10 \mathrm{keV} . b$ ) То же в другом временно́м масштабе.

ные различия. Экспериментальные результаты измерений кинетики зарядки исходного кристалла $\mathrm{SiO}_{2}$ и того же кристалла после предварительной электронной и ионной бомбардировки представлены на рис. 5 при энергии облучающих электронов $E_{0}=5 \mathrm{keV}$ и плотности тока $j_{0}=10^{-7} \mathrm{~A} \cdot \mathrm{cm}^{-2}$. Аналогичные измерения при энергии $E_{0}=15 \mathrm{keV}$ приведены на рис. 6 . На рис. $5, b$ и $6, b$ представлены результаты измерений в первые моменты облучения.

$\mathrm{B}$ отличие от $\mathrm{Al}_{2} \mathrm{O}_{3}$ (сапфира) для $\mathrm{SiO}_{2}$ не замечено большой разницы в кинетике зарядки исходного образца и образца, предварительно облученного ионами $\mathrm{Ar}^{+}$. И вновь проявляется более медленная стадия зарядки образцов, подвергнутых предварительному электронному облучению (кривые 2 на рис. 5 и 6). Но в отличие от сапфира для $\mathrm{SiO}_{2}$ не обнаружено образования критического потенциала, а темп зарядки и поверхностный потенциал изменяются плавно за время, на порядки величины большее, чем для исходного и ионно-облученного образцов. 


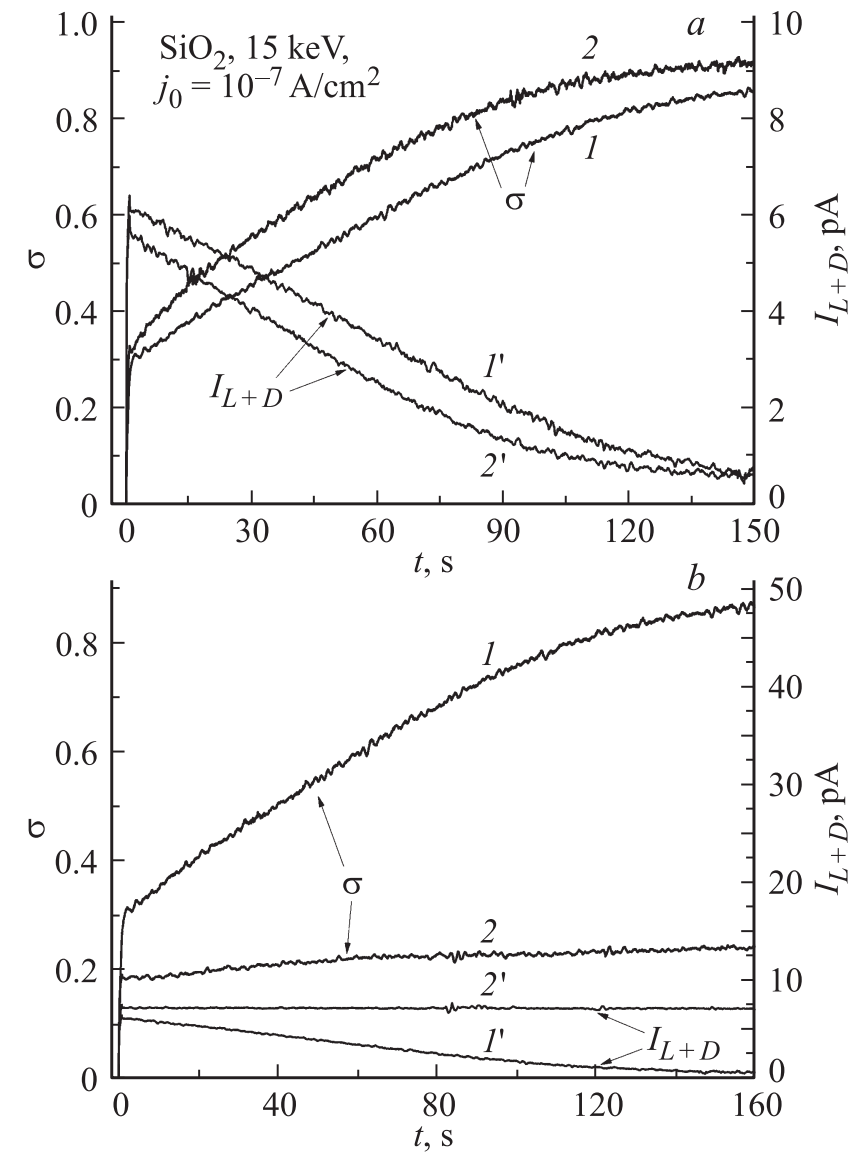

Рис. 7. Сравнение временны́х зависимостей коэффициента ВЭ $\sigma(t)(1,2)$ и тока смещения $I_{L+D}(t)\left(1^{\prime}, 2^{\prime}\right)$ для исходной $\left(1,1^{\prime}\right)$ и предварительно облученной $\left(2,2^{\prime}\right)$ ионами $(a)$ и электронами $(b)$ поверхности $\mathrm{SiO}_{2}$.

Различный характер для указанных образцов проявляют и зависимости коэффициентов ВЭ $\sigma$, а также токов смещения $I_{L+D}$ (рис. 7). Если после ионной бомбардировки зависимости $\sigma(t)$ (кривые 1 и 2 ) и $I_{L+D}(t)$ (кривые $1^{\prime}$ и $2^{\prime}$ ) совпадают с аналогичными зависимостями для исходного образца $\mathrm{SiO}_{2}$ (рис. 7,a), то после предварительного электронного облучения эти зависимости различаются (рис. 7, $b$ ). В последнем случае при низкой величине коэффициента $\sigma(t)$ (кривая 2) значение тока смещения (кривая $2^{\prime}$ ), определяющего величину аккумулированного заряда $Q_{t}=\int_{0}^{t} I_{L+D} d t$, больше, чем для исходного образца (кривая $1^{\prime}$ ).

\section{4. Обсуждение результатов}

Прежде всего рассмотрим те изменения на поверхности диэлектрических образцов (оксидов $\mathrm{SiO}_{2}$ и $\mathrm{Al}_{2} \mathrm{O}_{3}$ ), которые происходят под воздействием ионной и электронной бомбардировки.

Данные о формировании модифицированного слоя в оксидах кремния и алюминия при их облучении ионами низких и средних энергий довольно противоречивы. В ранних работах (см., например, [23]), посвященных изучению закономерностей преимущественного распыления оксидов, не было обнаружено изменения стехиометрического состава оксидов $\mathrm{SiO}_{2}$ и $\mathrm{Al}_{2} \mathrm{O}_{3}$. Однако в более поздних работах такое изменение наблюдалось. Автор работы [24] при помощи метода электронной спектроскопии для химического анализа, использующего синхротронное излучение, при бомбардировке ионами $\mathrm{Ar}^{+}$с энергией $2 \mathrm{keV}$ наблюдал формирование на поверхности $\mathrm{SiO}_{2}$ измененного слоя, содержащего оксид $\mathrm{SiO}_{x}(x=1.2)$. Толщина этого слоя по оценкам автора составляла примерно $0.4-0.9 \mathrm{~nm}$.

В работе [25] были проведены систематические исследования радиационных повреждений в $\mathrm{SiO}_{2}$, вызванных облучением ионами $\mathrm{Ar}^{+}, \mathrm{Ne}^{+}$и $\mathrm{He}^{+}$низких энергий $(70-500 \mathrm{eV})$. Исследования с помощью метода электронной Оже-спектроскопии (ЭОС) показали, что на поверхности формируется тонкий обедненный кислородом слой, толщина которого оценивалась как 0.5-0.7 nm. Обеднение поверхности $\mathrm{Al}_{2} \mathrm{O}_{3}$ кислородом под действием бомбардировки ионами $\mathrm{Ar}^{+}$с энергиями 200-2000 eV также наблюдалось экспериментально методом ЭОС в работе [26].

Основным механизмом дефектообразования в кристаллах $\mathrm{SiO}_{2}$ и $\mathrm{Al}_{2} \mathrm{O}_{3}$ при ионной бомбардировке является механизм ударного смещения. За пороговую энергию образования дефекта по механизму упругого смещения принимают кинетическую энергию, которую бомбардирующая кристалл частица должна передать покоящемуся в узле кристаллической решетки атому, чтобы он после столкновения с ней сместился на расстояние, исключающее при низких температурах его рекомбинацию с образовавшимся пустым узлом (вакансией). Для $\mathrm{SiO}_{2}$ энергия смещения для атомов O составляет $16.5 \mathrm{eV}$, а для атомов $\mathrm{Si}-33 \mathrm{eV}$. Экспериментальные оценки для кристалла $\mathrm{Al}_{2} \mathrm{O}_{3}$, приведенные в работе [27], дали значения 50 и $100 \mathrm{eV}$ для атомов алюминия и кислорода соответственно.

Дефектообразование в кристалле приводит к созданию в запрещенной зоне диэлектрика дополнительных уровней, которые могут служить ловушками для электронов и дырок. Обрыв связей в решетке $\mathrm{SiO}_{2}$, например, приводит к созданию уровней в запрещенной зоне, локализованных на $0.8-0.9 \mathrm{eV}$ ниже дна зоны проводимости и соответственно выше валентной зоны [11]. Эти уровни служат мелкими ловушками для дырок и электронов. Глубокие ловушки - уровни, лежащие посередине запрещенной зоны, - связаны с примесными атомами в кристалле или со связью $\mathrm{Si}-\mathrm{Si}$ в кристаллах, обогащенных кремнием. В кристалле $\mathrm{Al}_{2} \mathrm{O}_{3}$ [28] с вакансией алюминия $\left(V_{\mathrm{Al}}\right)$ связан глубокий акцепторный уровень, расположенный на $2.6 \mathrm{eV}$ выше потолка валентной зоны. Энергетический уровень междоузельного атома алюминия $\left(\mathrm{Al}_{i}\right)$ лежит примерно на $2 \mathrm{eV}$ ниже зоны проводимости и является глубоким донорным уровнем. Кислородные вакансии $-F$-центры - ассоциированы 
с уровнями, локализованными в середине запрещенной зоны, и акцепторным уровнем на $1 \mathrm{eV}$ ниже дна зоны проводимости, в то время как междоузельные атомы кислорода $\mathrm{O}_{i}$ - это глубокие акцепторы с положением в середине запрещенной зоны.

Разрушение поверхности оксидов $\mathrm{SiO}_{2}$ и $\mathrm{Al}_{2} \mathrm{O}_{3}$ под действием бомбардировки электронами низких энергий $(1-3 \mathrm{keV})$ было экспериментально подтверждено в работе [9]. В результате ЭСД кислорода на поверхности этих материалов наблюдалось обеднение кислородом тонкого приповерхностного слоя толщиной $0.5-0.7 \mathrm{~nm}$. С помощью метода ЭОС были оценены сечения процесса ЭСД для $\mathrm{SiO}_{2}$ и $\mathrm{Al}_{2} \mathrm{O}_{3}$, которые составили $10^{-21}$ и $10^{-22} \mathrm{~cm}^{2}$ соответственно. Для кристалла $\mathrm{Al}_{2} \mathrm{O}_{3}$ было также обнаружено формирование металлических островков алюминия. Образование на поверхности $\mathrm{Al}_{2} \mathrm{O}_{3}$ после бомбардировки низкоэнергетическими электронами островковой металлической пленки с размерами островков 50-70 nm также наблюдалось в работе [18] с помощью атомно-силовой микроскопии.

Для объяснения ЭСД с поверхности оксидов $\mathrm{SiO}_{2}$ и $\mathrm{Al}_{2} \mathrm{O}_{3}$ был привлечен механизм КФ. Одним из критериев применимости этой модели ЭСД является степень ионности соединения, которая составляет 51\% для $\mathrm{SiO}_{2}$ и $63 \%$ для $\mathrm{Al}_{2} \mathrm{O}_{3}$, откуда следует, что $\mathrm{SiO}_{2}$ должен быть более радиационно-стойким по сравнению с $\mathrm{Al}_{2} \mathrm{O}_{3}$. Однако экспериментально найденное сечение ЭСД для $\mathrm{SiO}_{2}$ на порядок больше, чем для $\mathrm{Al}_{2} \mathrm{O}_{3}$, что позволяет предположить существование дополнительного механизма электронно-стимулированной десорбции для $\mathrm{SiO}_{2}$. Например, можно привлечь экситонный механизм.

Экситонный механизм создания радиационных дефектов за счет возбуждения электронной подсистемы кристалла был предложен в работах $[30,31]$ для объяснения ЭСД в щелочно-галоидных кристаллах. Согласно этой модели, электронный пучок, падая на поверхность кристалла, возбуждает его электронную подсистему, в результате чего в кристалле формируются электроннодырочные пары и экситоны. Эти возбуждения за счет локального экситон-фононного взаимодействия локализуются, образуя автолокализованные экситоны. Автолокализованный экситон представляет собой электрон и двухгалоидный молекулярный ион, расположенный в двух анионных узлах. Возбужденное состояние такого автолокализованного экситона нестабильно относительно сдвига вдоль кристаллографической оси $\langle 100\rangle$. В результате автолокализованный экситон безызлучательно распадается на френкелевскую пару: $F$-центр (анионная вакансия с захваченным электроном) и $H$-центр (молекулярный ион $X^{2-}$, занимающий анионный узел). Следует отметить, что порог дефектообразования в этой модели оказывается меньше ширины запрещенной зоны. Образование дефектов в $\mathrm{SiO}_{2}$ за счет электронных возбуждений под воздействием электронной бомбардировки экспериментально наблюдалось в работах [32,33].

Таким образом, наблюдаемые в эксперименте необычные кинетические характеристики зарядки кристалла
$\mathrm{SiO}_{2}$ электронным зондом, возможно, связаны с модификацией его поверхности и радиационно-стимулированным дефектообразованием по приведенным здесь механизмам в ходе предварительной ионной и электронной бомбардировки.

Рассмотрим далее детально особенности зарядки электронным пучком кристалла $\mathrm{SiO}_{2}$, предварительно облученного электронами, которые объясняются эффектом рассеяния зарядов. При предварительной бомбардировке участка поверхности $\mathrm{SiO}_{2}$ (диаметр пятна облучения равен $3 \mathrm{~mm}$ ) электронами с энергией $3 \mathrm{keV}$ и дозой $10^{18} \mathrm{~cm}^{-2}$ происходит модификация поверхности, сопровождаемая образованием радиационно-стимулированных дефектов ( $E^{\prime}$-центров). При этом поверхностное удельное сопротивление на облученном участке падает [34-36]. При проведении измерений кинетики зарядки $\mathrm{SiO}_{2}$ в СЭМ проводится электронное зондирование площадки размером $100 \times 100 \mu \mathrm{m}$ в центре предварительно облученного пятна диаметром $3 \mathrm{~mm}$. После набора определенной дозы облучения и соответственно заряда аккумулированных электронов созданное поле зарядов достигает такого критического значения $F_{\text {cr }}$, которое достаточно для возникновения прыжковой проводимости электронов по поверхности (по механизму Пула-Френкеля $[3,34,36])$. В результате электроны быстро „расплываются“ из заряжаемого участка размером $100 \times 100 \mu \mathrm{m}$ до границ большого ранее облученного пятна. При этом рост поверхностного потенциала $V_{s}(t)=Q_{t}(t) / C(t)$ происходит за более длительное время, чем в случае зарядки исходного образца (рис. 6). Здесь $C-$ емкость.

Оценим эту разницу во времени зарядки следующим образом. Примем, что потенциал $V_{s}$ в центре однородно заряженного диска диаметром $a$ равен [1]

$$
V_{s}[\mathrm{~V}]=\frac{Q_{t}(C)}{\pi\left(1+\varepsilon_{r}\right) \varepsilon_{0} a[\mathrm{~cm}]},
$$

где $\varepsilon_{0}=8.85 \cdot 10^{-12} \mathrm{~F} \cdot \mathrm{m}^{-1}, \varepsilon_{r}=4$ (для $\mathrm{SiO}_{2}$ ).

При полном заряде $Q_{t}=0.32 \mathrm{nC}$ на облученном диске диаметром $a=100 \mu \mathrm{m}$ потенциал поверхности исходного образца достигает равновесного значения $V_{s} \approx-12 \mathrm{kV}$ (при $E_{0}=15 \mathrm{kV}$ ) за время $200 \mathrm{~s}$ (рис. $6 a$, кривая 1). Но при измерениях потенциала, при которых происходит сканирование участка поверхности размером $100 \times 100 \mu \mathrm{m}$, расположенного в центре предварительно облученного электронами пятна, наблюдается на порядок величины большее время зарядки (> $2500 \mathrm{~s}$, рис. 6, $a$, кривая 2). Это различие объясняется, как было отмечено выше, эффектом растекания заряда из облученной области диаметром $a$, т.е. распространением электронов из этой области по поверхности до границ большого изначально облученного пятна диаметром $L=3 \mathrm{~mm}$ (рис. 8). Аккумулируемый в этой ситуации заряд равен $Q_{t}=9.7 \mathrm{nC}$, что в пределе дает тот же равновесный потенциал $V_{s}$ порядка $-12 \mathrm{keV}$, но за время зарядки $5 \cdot 10^{3} \mathrm{~s}$. Эта оценка согласуется с 


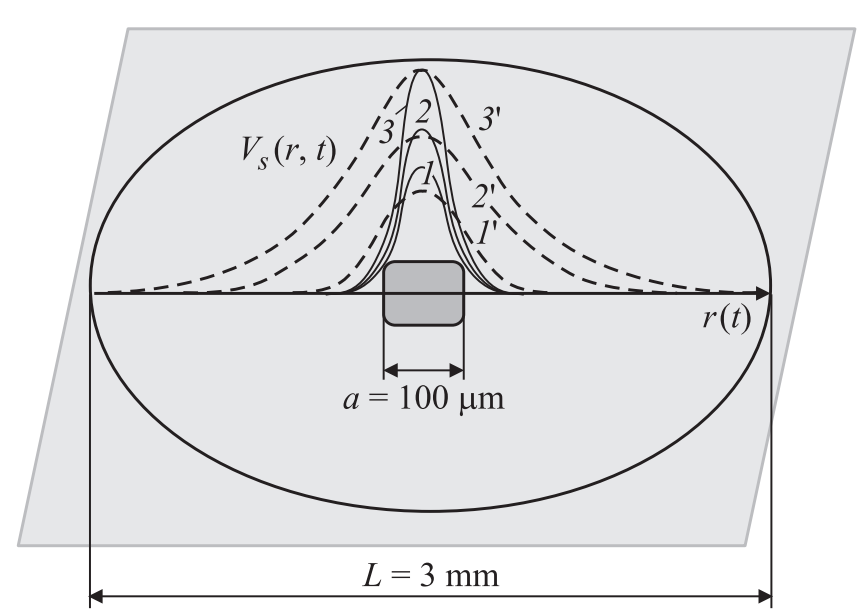

Рис. 8. Схема растекания зарядов по поверхности $\mathrm{SiO}_{2}$ и связанные с ними поверхностные потенциалы. 1-3 - потенциалы поверхности $V_{s}(r, t)$ для исходного кристалла в различные моменты времени, $1^{\prime}-3^{\prime}-$ потенциалы поверхности для предварительно облученного кристалла.

расчетной величиной, вычисленной по формуле (2) при $a=L=3 \mathrm{~mm}$.

Такое поведение кинетики $V_{s}(t)$ можно объяснить по аналогии с зарядкой емкости $C$, которая пропорциональна площади заряженной поверхности. В рассматриваемом случае (см. формулу (2)) емкости пропорциональны соответственно размерам областей $a=100 \mu \mathrm{m}$ и $L=3 \mathrm{~mm}$, причем $L / a=30 \approx Q_{L} / Q_{a}$, где $Q_{L}$ и $Q_{a}-$ аккумулируемые заряды на площадях с линейными размерами $L$ и $a$. На рис. 8 представлена условная схема растекания зарядов и связанные с ними поверхностные потенциалы, имеющие в общем случае гауссову форму распределения. В исходном кристалле потенциал $V_{s}(r, t)$ растет довольно быстро со временем (кривые $1-3)$. Но в предварительно облученном кристалле вследствие „расплывания“ электронов по большей площади требуется большее время $t^{\prime}$ для установления равновесного потенциала $V_{s}\left(r, t^{\prime}\right)=$ const при $r=L / 2: t^{\prime} \gg t$ (кривые $\left.1^{\prime}-3^{\prime}\right)$. Отметим еще раз, что в процессе облучения заряды заполняют все пространство большого пятна (3 mm) очень быстро (за время растекания электронов по прыжковому механизму для наноструктур), но общий процесс зарядки вследствие увеличения площади облучения, а тем самым и емкости при неизменной плотности тока $j_{0}$ идет в несколько раз дольше (за время порядка нескольких минут).

\section{5. Заключение}

В работе изучались различия кинетики зарядки электронным пучком исходной поверхности диэлектриков и поверхности, подвергнутой предварительно электронному и ионному воздействию.
Наблюдаемое экспериментально резкое различие времен зарядки исходного и облученного ионами сапфира объясняется генерацией радиационно-стимулированных дефектов, являющихся ловушками для электронов, что подтверждается экспериментами по измерению интенсивности катодолюминесценции.

Обнаружено, что кинетика зарядки предварительно облученного электронами сапфира различается в случае измерений при 5 и $15 \mathrm{keV}$. При энергии облучающих электронов $E_{0}=5 \mathrm{keV}$ характер зарядки аналогичен наблюдаемому для сапфира, предварительно облученного ионами $\mathrm{Ar}^{+}$. При энергии электронов $E_{0}=15 \mathrm{keV}$ сапфир быстро заряжается до некоторого критического потенциала $V_{s}=-2.5 \mathrm{kV}$, после чего процесс зарядки резко замедляется, и потенциал поверхности достигает равновесного значения спустя время, значительно большее, чем при зарядке исходного сапфира.

$\mathrm{B}$ отличие от сапфира для $\mathrm{SiO}_{2}$ не замечено большой разницы в кинетике зарядки исходного образца и образца, предварительно облученного ионами $\mathrm{Ar}^{+}$. В то же время кинетика зарядки предварительно облученного электронами образца обнаруживает особенность: темп зарядки и поверхностный потенциал изменяются плавно за время, на порядки величины большее, чем для исходного и ионно-облученного образцов. Это различие объясняется, вероятно, эффектом растекания заряда из облученной области по поверхности до границ большого изначально облученного электронами пятна $\mathrm{SiO}_{2}$-мишени.

\section{Список литературы}

[1] J. Cazaux. J. Appl. Phys. 89, 8265 (2001).

[2] A. Melchinger, S. Hofmann. J. Appl. Phys. 78, 6224 (1995).

[3] N. Cornet, D. Goeuriot, C. Guerret-Piecourt, D. Juve, D. Treheux, M. Touzin, H.-J. Fitting. J. Appl. Phys. 103, 064110 (2008).

[4] B. Askri, R. Renoud, K. Raouadi, J.-P. Ganachaud. Eur. Phys. J. Appl. Phys. 32, 29 (2005).

[5] Э.И. Рау, Е.Н. Евстафьева, М.В. Андрианов. ФТТ 50, 599 (2008).

[6] Е.Н. Евстафьева, Э.И. Рау, А.А. Татаринцев. Вестн. МГУ. Cер. 3. Физика, астрономия 2, 34 (2013).

[7] E.I. Rau, S. Fakhfakh, M.V. Andrianov, E.N. Evstafeva, O. Jbara, S. Rondot, D. Mouze. Nucl. Instr. Meth. Phys. Res. B 266, 719 (2008).

[8] F. Lefebre, J.P. Vigouroux, J. Perreau. J. Appl. Phys. 65, 1683 (1989).

[9] R.A. Baragiola, M. Shi, R. Vidal, C. Dukes. Phys. Rev. B. 58, 13212 (1998).

[10] E. Cheifetz, V. Richter, A. Zalman, R. Kalish. Diamond. Relat. Mater. 10, 824 (2001).

[11] S. Yogev, J. Levin, M. Molotskii, A. Schwarzman, O. Avayu, Y. Rosenwaks. J. Appl. Phys. 103, 064107 (2008).

[12] A. Hoffman, S. Prawer, R. Kalish. Phys. Rev. B 45, 12736 (1992).

[13] E.I. Rau, A.A. Tatarintsev, V.V. Khvostov, V.E. Yurasova. Vacuum 129, 142 (2016). 
[14] Распыление твердых тел ионной бомбардировкой / Под ред. Р. Бериша. Мир, М. (1986). В. 2. 488 с.

[15] R. Kelly. J. Vac. Sci. Technol. 21, 778 (1982).

[16] N.V. Alov. Phys. Status Solidi C 12, 263 (2015).

[17] M.L. Knotek, P.J. Feibelman. Surf. Sci. 90, 78 (1979).

[18 ] Е.Ю. Зыкова, А.А. Хайдаров, И.П. Иваненко, И.К. Гайнуллин. Поверхность. Рентгеновские, синхротронные и нейтронные исследования 11, 7 (2012).

[19] K.F. Minnebaev, V.V. Khvostov, E.Yu. Zykova, K.A. Tolpin, J.S. Colligon, V.E. Yurasova. Nucl. Instr. Meth. Phys. Res. B 354, 159 (2015).

[20] J.P. Vigouroux, J.P. Duraud, A. Le Moel, C. Le Gressus. J. Appl. Phys. 57, 5139 (1985).

[21] G. Blaise, C. Le Gressus. J. Appl. Phys. 69, 6334 (1991).

[22] В.В. Никитин, П.В. Комолова, Э.И. Рау. Опт. и спектр. 60, 1186 (1986).

[23] K.S. Kim, W.E. Baitinger, J.W. Amy, N. Winograd. J. Electron. Spectrosc. 5, 351 (1974).

[24] E. Paparazzo. J. Electron. Spectrosc. 50, 47 (1990).

[25] M. Khellafi, B. Lang. Rev. de Phys. Appl. (Paris) 25, 389 (1990).

[26] M.B. Guseva, V.V. Khvostov, V.M. Kostishko, S.Yu. Kovalenko. Surf. Sci. Lett. 276, L24 (1992).

[27] P. Levy. Phys. Rev. 123, 1226 (1961).

[28] M. Choi, A. Janotti, Ch.G. Van de Walle. J. Appl. Phys. 113, 044501 (2013).

[29] O.V. Rakhovskaya, S.S. Elovikov, E.M. Dubinina, E.S. Shakhurin, A.P. Dementjev. Surf. Sci. 274, 190 (1992).

[30] D. Pooley. Proc. Phys. Soc. 87, 245 (1966).

[31] Ч.Б. Лущик, И.К. Витол, М.А. Эланго. ФТТ 6, 2753 (1968).

[32] K. Tanimura, T. Tanaka, N. Itoh. Phys. Rev. Lett. 51, 423 (1983).

[33] M.A. Stevens-Kalceff. Phys. Rev. Lett. 84, 3137 (2000).

[34] A. Crisci, B. Gosse, J.-P. Gosse, V.O. Dureault. Eur. Phys. J. Appl. Phys. 4, 107 (1998).

[35] R. Hanna, T. Paulmier, M. Belhaj, P. Molinie, B. Dirassen, P. Payan, N. Balcon. J. Phys. D 44, 445402 (2011).

[36] B.N. Hendriks, G. van Gorkom, A. van Keersop, N. Lambert, S.T. de Zwart. J. Appl. Phys. 85, 1848 (1999). 